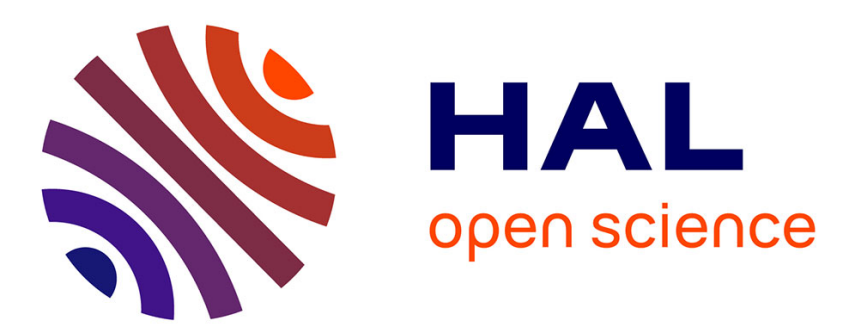

\title{
Involuntary Unemployment in Imperfectly Competitive General Equilibrium Models
}

Laurence Lasselle, Serge Svizzero

\section{To cite this version:}

Laurence Lasselle, Serge Svizzero. Involuntary Unemployment in Imperfectly Competitive General Equilibrium Models. Journal of Economic Surveys, 2002, 16 (4), pp.487-507. 10.1111/14676419.00175 . hal-02163252

\section{HAL Id: hal-02163252 \\ https://hal.univ-reunion.fr/hal-02163252}

Submitted on 24 Jun 2019

HAL is a multi-disciplinary open access archive for the deposit and dissemination of scientific research documents, whether they are published or not. The documents may come from teaching and research institutions in France or abroad, or from public or private research centers.
L'archive ouverte pluridisciplinaire $\mathbf{H A L}$, est destinée au dépôt et à la diffusion de documents scientifiques de niveau recherche, publiés ou non, émanant des établissements d'enseignement et de recherche français ou étrangers, des laboratoires publics ou privés. 


\title{
INVOLUNTARY UNEMPLOYMENT IN IMPERFECTLY COMPETITIVE GENERAL EQUILIBRIUM MODELS
}

\author{
Laurence S. Lasselle \\ CRIEFF, University of St Andrews \\ Serge A. Svizzero \\ CERESUR, Université de la Réunion, France
}

\begin{abstract}
This paper is about 'involuntary unemployment' in general equilibrium models with imperfect competition. It surveys papers written after the seminal work of d'Aspremont, Dos Santos Ferreira and Gérard-Varet (1984). This unemployment is called involuntary because it exists at any wage. It results from imperfect competition in the product markets, more specifically from firms' excessive market power. These papers have focussed their attention on the conditions required for involuntary unemployment. In our presentation, we characterise this form of unemployment through three elements: consumers' preferences, price expectations and Ford effects. Each element is important because it influences the demand for the good and hence its price elasticity, the latter being central in the definition of firms' market power. JEL Classification. D43, E24.
\end{abstract}

Keywords. Expectations; Ford effects; Imperfect competition; Preferences; Priceelasticity; Unemployment.

\section{Introduction}

This paper surveys the literature on 'involuntary unemployment' in imperfectly competitive general equilibrium models. This unemployment is called involuntary because it exists at any wage. It results from imperfect competition in the product markets, more specifically from firms' excessive market power. This concept is interesting since unemployment can arise without the usual requirement of an imperfect labour market. Depending on the framework its occurrence has been connected with three main ingredients: the consumer's preferences, the nature of expectations and the income feedback effects. Unfortunately this interesting concept seems not to be widely known and this survey aims to give an evaluative insight into this theory of involuntary unemployment.

This literature, initiated by d'Aspremont et al. (1984) with the first paper published by Dehez (1985), has developed alongside the more mainstream New 
Keynesian papers. It is one of several micro-based explanations of why the labour market cannot clear and hence why an aggregate excess supply of labour can arise (some of these explanations are given in Bénassy, 1987; Blanchard and Kiyotaki, 1987). As in many New Keynesian theories (Mankiw and Romer, 1991; Dixon and Rankin, 1995), this approach addresses the issue of involuntary unemployment (which will be denoted thereafter by IU), i.e. it tries 'to explain why unemployed workers are, for long periods, unable to get jobs on the same conditions as, or even at lower wages than actually employed workers with the same ability' (Lindbeck, 1998, p. 168). However, when in New Keynesian theories unemployment is called 'involuntary', it is not in the sense we develop in this paper. Indeed, in these theories, unemployment always comes from a wage set at a level higher than the competitive wage. It is perceived as a result of the existence of trade unions in the labour market (Hart, 1982) or of the implementation of efficiency wages by firms (Yellen, 1984). Here, we consider an alternative explanation of IU. It is not associated with an excessive wage level. It does not result from the imperfection of the labour market nor from wage or price stickiness. The title of Silvestre's (1990) paper (i.e. 'There may be unemployment when the labour market is competitive and the output market is not') clearly explains this feature. In fact, IU comes from firms' excessive market power. In other words, a non-competitive product market is sufficient to generate unemployment which is therefore 'involuntary'.

There are two main reasons why this approach is interesting. First, in a purely classical framework (including rational and maximising agents, free markets and flexible prices) identical to that used by New Keynesian economists, it leads to a notion of unemployment which really has a Keynesian flavour. Second, it shows that when there is unemployment, economic policies based on increasing wage and labour market flexibility may be totally ineffective if unemployment is involuntary. So, even if the framework is classical, the policy implications are Keynesian. The concept of IU in that context is then rather powerful and it is regrettable that little attention has been paid to this approach so far.

There are two reasons that may explain this lack of interest. On the one hand, the concept of IU is confusing. Since Keynes, many interpretations of IU have been given, especially during the last decade by proponents of the New Keynesian School. In this survey, we will discuss IU when unemployment exists despite a zero wage or, by extension, when unemployment exists at any wage. On the other hand, the existing papers we survey have argued the possibility (or the impossibility) of IU in different frameworks. Indeed the occurrence of IU has been studied in static models as well as in dynamic models based on overlapping generations of consumers. Each framework has its own features to explain the possibility of IU. So, in the overlapping generations framework, two specific elements influence the existence of IU: first, price expectations (because the model is dynamic) and second, consumers' preferences (with at least two generations in each period, consumers are no longer homogeneous). But a common feature can be found between the different frameworks: the structure of the economy, namely the number of markets and the links between them. Indeed, through the income 
distribution the structure of the economy influences the link between the supply and demand of the product, i.e. it determines the size of Ford effects. ${ }^{1}$ The absence of a common framework has not facilitated the understanding, the evaluation and the 'promotion' of this literature.

This survey aims to give an evaluative insight of this theory of IU. For that purpose, it presents the existing results in a single framework. This single framework allows us to evaluate the different results in a more appropriate way.

The concept of IU and its implications are developed in the second section. The third section is devoted to the study of elements which determine the existence of IU.

\section{The concept of involuntary unemployment: definition and implications}

In general equilibrium models with imperfect competition, the notion of IU was first introduced by d'Aspremont et al. (1984). Following this seminal work, a small group of papers, the first published being Dehez (1985), studied the conditions for the existence of IU in various general equilibrium models.

Before going any further we need to put this literature into historical context. Indeed, this literature is one of many developments initiated by Hart's (1982) paper. Hart brought up a macroeconomic question (unemployment) in a framework with microeconomic foundations (optimisation behaviour of the agents). He was the first to study the occurrence of underemployment in imperfectly competitive general equilibrium models. It is the critique of his results that originated the literature we review.

In Hart's model, two assumptions are crucial. On the one hand, the economy contains a parameterised number of local markets (or sectors), including products as well as labour markets. Thus, the market power of any agent (firm or trade union) is inversely correlated to the number of markets. In the papers we review, this assumption has been adapted in order to evaluate the impact of Ford effects on IU. On the other hand, in contrast to Negishi's (1961) subjectivist approach, the imperfect competitors are assumed to know the objective or 'true' demand ${ }^{2}$ they face.

Hart's main result has a Keynesian flavour: fiscal policy is fully effective even when prices are perfectly flexible. An expansionary fiscal policy implies more output and employment without inflation. Indeed, a balanced-budget fiscal policy can be used to stimulate the economy because a standard Keynesian-type multiplier of money on output exists. Complete price rigidity appears to be a result associated with unions' behaviour under Cournot competition. However, it was demonstrated (see for instance Bénassy, 1994) that this ultra-Keynesian result was not robust. As in the textbook Keynesian model, ${ }^{3}$ it requires an inelastic aggregate supply function. For this purpose, specific assumptions ${ }^{4}$ are required in a micro-based model. When at least one of these assumptions is relaxed, fiscal policy also involves inflationary pressure. Although Hart's policy implication was Keynesian, his explanation of unemployment was not. Indeed, it was connected with the presence of trade unions in the labour markets, i.e. one of the numerous possible reasons explaining why the wage level exceeds the competitive wage. 


\subsection{Definition of involuntary unemployment}

D'Aspremont et al. contested the 'Neo-Classical' explanation of unemployment given by Hart. To the question 'Is unemployment possible even with a flexible wage?', they answered 'Yes' while Hart argued that unemployment came from wage rigidities.

With a perfectly flexible wage, unemployment appears when the labour supply curve and the labour demand curve do not intersect. In such a case, at any wage there is an excess supply of labour at the equilibrium. Specific assumptions are required to get such an equilibrium. The labour supply function must be inelastic. On the demand side, a competitive labour demand function is excluded when the technology is standard. ${ }^{5}$ Indeed, for a wage close to zero, the competitive labour demand is infinite. By continuity, there exists a wage level such that full employment prevails. Thus, when firms are imperfect competitors, the level of their labour demand can be, at any wage, less than the inelastic labour supply. This will appear when, contrary to Hart (1982, p. 117, assumption A7), the firm's marginal revenue takes negative values for large output levels.

This assumption due to d'Aspremont et al. is crucial in generating IU. Indeed, let us assume that there is (non-involuntary) unemployment. Then, the wage decreases and the marginal cost tends to zero. The profit function tends to the total revenue function. Under Hart's assumption (A7), the marginal revenue is always positive and then there exists a positive level of output which maximises the firm's profit and leads to a full employment equilibrium. Under d'Aspremont et al.'s assumption, the profit of the representative firm is maximised for a finite output level (when the marginal revenue vanishes) but this output level does not necessarily imply full employment. Note that their conclusion is independent of the wage level.

Both cases are illustrated in Figures 1 and 2. The economy's labour endowment is assumed to be uniformly distributed across firms. The firm's output at the full employment equilibrium (i.e. the vertical line) is then deduced. For simplicity the marginal cost is assumed to be constant and is equal to the nominal wage, i.e. the horizontal line. It shifts downward as the nominal wage tends to zero. The firm's output at equilibrium is given by the intersection of the marginal revenue curve and the marginal cost line. In Hart's case (see Figure 1), when the wage tends to zero, the firm's output level tends to the full employment output level. In the case studied by d'Aspremont et al. (see Figure 2), the highest level of the firm's output is the one for which the marginal revenue vanishes, i.e. it is obtained for a marginal cost (and then a nominal wage) equal to zero. As in Figure 2, this output level can be less than the full employment output level. So, at any wage (even a zero wage), full employment is never reached.

From the above discussion we can deduce that two conditions are required for IU to appear. The first condition is about the level of the labour supply while the second condition is about the marginal revenue function.

CONDition (C1) The (fixed) level of the labour supply must be larger than the highest level of the labour demand (the latter being associated with a zero wage). 


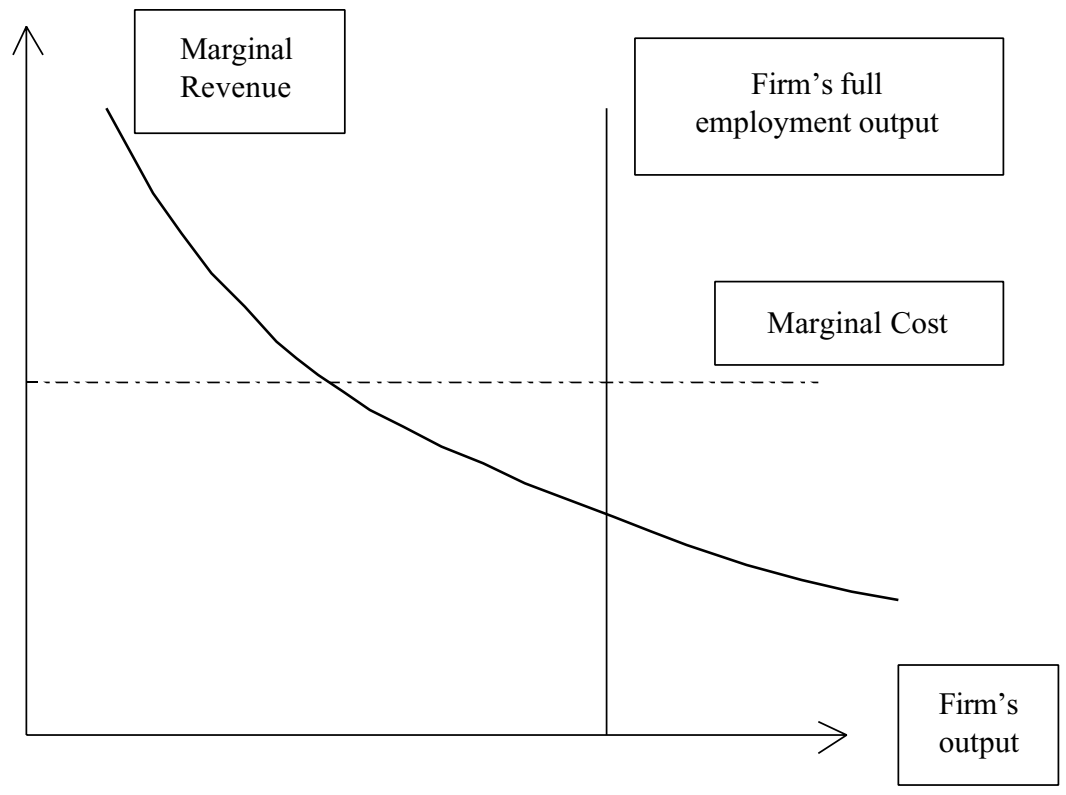

Figure 1. Marginal revenue according to Hart (1982) and the full employment equilibrium.

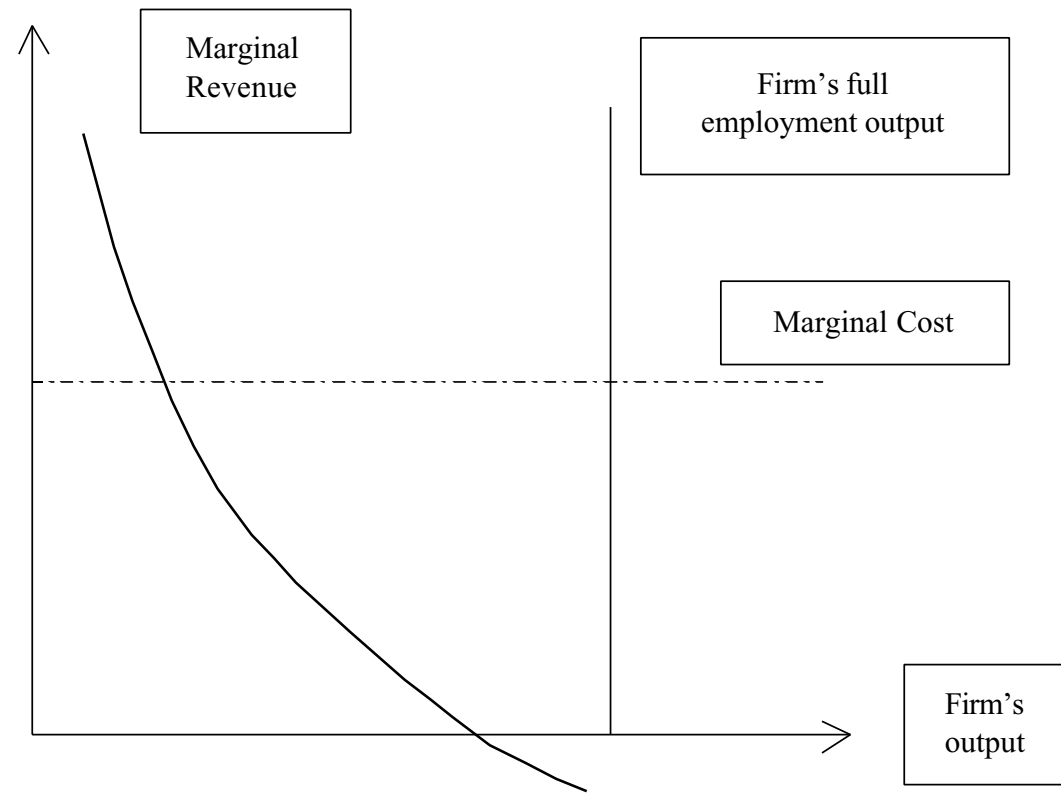

Figure 2. Marginal revenue according to d'Aspremont et al. (1984) and involuntary unemployment. 
CONDITION (C2) Considered as a function of output, the marginal revenue must be a strictly decreasing function and must intersect the horizontal axis.

When (C2) is met, the total revenue function is unimodal, i.e. it admits a unique (global) maximum. The firm's supply function is strictly increasing and is also upper bounded. Indeed, the firm cannot produce an output level larger than the output level associated with a zero marginal revenue. As stated above when the wage decreases and tends to zero, the profit function is associated with the total revenue function. The total revenue is maximised for a fixed level of output directly deduced from the zero level of marginal revenue. The different cases under which condition (C2) is fulfilled and related to consumers' preferences, expectations and Ford effects are studied in Section 3. Condition (C1) is trivial but nevertheless necessary because full employment would prevail if the marginal revenue was nil for an output level larger than the full employment output level. Of course this condition is the basic postulate introduced by d'Aspremont et al., it is not easy to explain on empirical grounds why it is a reasonable condition. ${ }^{6}$

DEFINITION Unemployment is involuntary when it exists at any wage, including a zero wage.

It should be noted that the existence of IU requires an exogenous and inelastic labour supply. When this strong assumption is relaxed, IU stricto sensu disappears but, as considered by Silvestre (1993, p. 114-15), two additional realistic and interesting cases emerge. In both cases it is assumed that labour has disutility. First, there may exist a positive reservation wage. When the labour demand intersects the labour supply on its horizontal part, there is unemployment even if the wage is adjusted to its lower level, i.e. to the reservation wage. Second, if a wage-taking supply of labour is considered, then full employment prevails.

\subsection{The relevancy of involuntary unemployment or is this unemployment really involuntary?}

D'Aspremont et al. chose the label 'involuntary unemployment' with reference to Keynes because this unemployment exists at any wage, i.e. 'there is no method available to labour as a whole' for attaining full employment 'by making revised money bargains with the entrepreneurs' (see Keynes, 1936, p. 13). However this label is confusing because many other interpretations of IU have been given.

De Vroey (1999) considered that there is IU in the Keynesian sense when a worker does not get a job although the (equilibrium) real wage exceeds his reservation wage. In d'Aspremont et al., the labour supply function is totally inelastic, therefore the reservation wage is zero. The real wage also equals zero when there is unemployment. Hence the unemployment they study is not involuntary because the reservation wage equals the real wage. 
Dixon and Rankin (1994) argued in the same direction. They pointed out that leisure was not present in the utility function. So, when the wage is equal to zero, agents are indifferent between working and not working. If they choose the latter, then unemployment is clearly voluntary. Moreover, they showed that under d'Aspremont et al.'s assumptions (an inelastic labour supply function and an upper bounded labour demand), the smallest amount of wage rigidity would be enough to cause true involuntary unemployment (in Keynes' sense, simply because the fixed and positive real wage will be larger than the zero reservation wage).

It can then appear that the particular concept of IU may disappear by this 'endless semantic discussion'. In order to avoid any further recognition problems, it seems preferable to refer, as Silvestre (1993) did, to the notion of 'unemployment at all wages'. However, in what follows we will continue to use the label IU.

Finally, if this literature on IU is not very popular among economists it is also because it describes an unrealistic situation. When the labour market is competitive, IU corresponds to an excess supply of labour despite a zero wage. From a theoretical point of view, labour becomes a free good, a situation never encountered in concrete economies. This approach to IU must then be considered as a 'purely hypothetical case'. However, it helps to understand how concrete economies work.

When there is IU, the real wage is nil and therefore less than the marginal product of labour (which is positive for standard technology). Following Pigou (1920) and Robinson (1933, chapter 25), Silvestre (1990) noted that this is a case of extreme exploitation of workers. Unionisation can then be seen as providing countervailing power to firms' exploitative power derived from imperfect product markets. The existence of IU can also be considered as a gross form of inefficiency because a useful, costless resource is wasted. Policy interventions are then justified. They may concern the demand side (through an expansionary budget policy) as well as the supply side (through the reduction of firms' market power). At this stage, the literature on IU has given little attention to these policy implications.

\section{Conditions for involuntary unemployment}

In the previous section we defined two conditions which are required for IU to appear. Condition (C2) is about the firm's marginal revenue. As a function of output, the marginal revenue must be decreasing and must also take positive and negative values. This condition is met independently of the kind of (imperfect) competition prevailing in the product market. In the related literature, the existing papers considered price setting competition (monopoly or monopolistic competition) (Dehez, 1985; d'Aspremont et al., 1990, 1991) and also quantity setting competition (d'Aspremont et al., 1984, 1989a, 1989b, 1991; Kaas, 1998; Lasselle and Svizzero, 1998, 2001; Schultz, 1992; Silvestre, 1990). In other words, the choice of the firm's strategic variable only has a second-order influence on the 
existence of IU. Indeed, the firm's marginal revenue always contains two components, namely the firm's market share and the price elasticity of the demand for the good. Without loss of generality, we restrict our analysis in what follows to quantity setting competition (or Nash-Cournot competition). In fact, this market structure was the first market structure studied by Hart (1982) and also by d'Aspremont et al. (1984).

In order to facilitate the understanding of our presentation we first give the algebric formulation of IU. Secondly we will review the three main features which lead to the possibility of IU.

\subsection{Algebric formulation of the involuntary unemployment condition (C2)}

We consider the market for a homogeneous commodity which is produced by $n \geqslant 2$ firms competing in a Nash-Cournot manner. The demand for the good is denoted $D(p)$ and is a decreasing function of the price, i.e. $D^{\prime}(p)<0$ where $D^{\prime}($.$) is$ the first derivative w.r.t. the price. Moreover we assume that $\lim _{p \rightarrow 0} D(p)=\infty$, that is to say the demand is not upper bounded when the price tends to zero. This assumption allows us to avoid a situation of trivial IU. Indeed, Novshek (1985) assumed that the demand was finite at a nil price. Then, IU comes from the excess of the full employment output level over the largest level of the demand for the good. Finally, we denote by $\varepsilon_{D}(p)=-p\left(D^{\prime}(p) / D(p)\right)$ the price elasticity of the demand for the good, which is strictly positive.

In a Cournot market, the firm's profit maximisation problem yields to the 'good old' first-order condition 'marginal revenue equals marginal cost', the latter is denoted by $M C$ (the right-hand term of (1)) and the former is denoted $M R$ (the left-hand term of (1)):

$$
p\left[1-\frac{1 / n}{\varepsilon_{D}(p)}\right]=M C(y)
$$

In equation (1), we implicitly assume that the equilibrium is symmetric ${ }^{7}$ and that the labour constraint is not binding at the equilibrium. ${ }^{8}$

The existence and uniqueness of the equilibrium are automatically established when the firm's profit function is concave. Two conditions are sufficient to ensure this concavity: the convexity of (identical) cost functions and the concavity of the demand for the good. When the latter condition is fulfilled, the marginal revenue (as a function of output) is decreasing and the price elasticity is increasing:

$$
D^{\prime \prime}(p)<0 \Longrightarrow \frac{\partial}{\partial y} M R(y)<0 \Longrightarrow \frac{\partial}{\partial p} \varepsilon_{D}(p)>0
$$

where $(\partial / \partial x) f($.$) is the partial derivative of function f$ with respect to the variable $x$ and $D^{\prime \prime}($.$) is the second derivative of the demand function.$ 
A few computations yield:

$$
\begin{gathered}
\frac{\partial}{\partial p} \varepsilon_{D}(p)=-\frac{D^{\prime}(p)}{D(p)}\left(1+\varepsilon_{D}(p)\right)-p \frac{D^{\prime \prime}(p)}{D(p)}>0 \text { if } D^{\prime \prime}(p)<0 \\
\frac{\partial}{\partial y} M R(y)<0 \Leftrightarrow \frac{\partial}{\partial p} M R(p)>0 \\
\text { but } \frac{\partial}{\partial p} M R(p)=\frac{1}{p}\left(M R(p)+\frac{\varepsilon_{D}^{\prime}(p)}{n\left(\varepsilon_{D}(p)\right)^{2}}\right)
\end{gathered}
$$

The last expression is strictly positive if $(\partial / \partial p) \varepsilon_{D}(p)>0$.

At this stage and especially given equation (1), the underlying model may be considered as a partial equilibrium story. However, it is not, i.e. the model is a general equilibrium model. Its general equilibrium nature comes from the interaction of two markets, namely the labour market and the produced good market. Even if the nominal wage determination is not specified, the two markets interact through the income feedback effects. ${ }^{9}$ Whatever the conjecture of firms about the size of these effects, these effects always exist. Indeed, wages and profits distribution on the one hand and consumption on the other hand prove that the equilibrium in one market depends on the equilibrium in the other market and vice-versa.

Starting from (1) we can clearly express the algebric formulation of condition (C2). This condition is met when the marginal revenue, on the one hand, is a decreasing function w.r.t. firm's output and, on the other hand, vanishes for a finite output level.

We previously showed that the first part of condition (C2) is necessarily fulfilled when the equilibrium exists. This result explains why the literature we review has focused its attention on the second part of condition (C2). Namely, this literature studies how firm's marginal revenue may take negative values at low prices. Its purpose is to establish conditions such that the price elasticity of the demand takes values less than $1 / n$, i.e. less than a firm's market share (see equation (1)).

The demand for the good plays a central part through its price elasticity. In the literature on IU, the aim is then to identify the components of the demand which have direct or indirect influences on the price elasticity. Currently, three main features have been studied: consumers' preferences, price expectations and Ford effects. In what follows we are going to study them separately and show their importance in the relevancy of the concept we review.

\subsection{Consumers' preferences and the structure of the population}

From now on, consumers are assumed to be 'price-takers'. 


\subsubsection{The representative consumer}

The demand function directly depends on consumers' preferences. With a loglinear utility function, condition (C2) is not met because the demand is unit-elastic $\left(\varepsilon_{D}(p)=1\right)$. For any number of firms in the market, the price elasticity exceeds the firm's market share and therefore the marginal revenue only takes positive values.

Silvestre (1990, p. 906-07) studied different utility functions leading to nonconstant price elasticities. With a CES utility function, the price elasticity is an increasing function of the price. It takes values which are positively correlated to the elasticity of substitution. When the goods are substitutes, the elasticity of substitution is larger than one but less than the price elasticity. Thus, the marginal revenue remains positive. When the goods are complements, the price elasticity is less than one but larger than the elasticity of substitution. Moreover, when the price decreases, the former elasticity converges to the constant value of the latter elasticity. By continuity, Silvestre demonstrated that IU can appear under strong complementarity.

D'Aspremont et al. (1989a, 1989b, 1990) gave examples of the occurrence of IU through a CES utility function. Silvestre (1990) also showed that the existence of IU is easier when the utility function has a variable elasticity of substitution.

\subsubsection{Heterogeneous consumers}

With heterogeneous agents the 'aggregate' demand is now a sum of individual demands and its properties are modified. The simplest case to present consists of two different consumers (or two groups of consumers). The aggregate demand $D(p)$ is the sum of the two individual demand functions, $F(p)+G(p)$. Its price elasticity is:

$$
\varepsilon_{D}(p)=\varepsilon_{F}(p) \frac{F(p)}{D(p)}+\varepsilon_{G}(p) \frac{G(p)}{D(p)}
$$

This is the sum of the price elasticities weighted by each demand relative to the aggregate demand.

In this case, it is possible to expand Silvestre's (1990) approach by assuming that each agent's utility function exhibits strong complementarity. However it is no longer possible to deduce from (2) information about the values taken by $\varepsilon_{D}(p)$. Indeed, even if individual demands are inelastic, the aggregate demand can be elastic because it is defined as the sum of the previous demands. Condition (C2) is then more unlikely to be verified when consumers are heterogeneous than when they are not.

Starting from this result, Schultz (1992) defined a case where IU cannot occur. For that purpose, he considered a dynamic model based on overlapping generations of consumers. Each consumer lives two periods, being young and then old. At every period the aggregate demand for the good is the sum of the demand of the young and the demand of the old. The old only consume on the 
basis of their money holding which corresponds to the fraction of the income saved when they were young. Their demand is simply the purchasing power of their money holding and its price elasticity equals unity. Schultz showed that the existence of an old generation weakens firms' market power and is sufficient to avoid the existence of IU. In addition to an overlapping generations framework, Schultz also assumed that there are no Ford effects and that price expectations are rational and inelastic. Both latter assumptions are crucial. Indeed, under alternative assumptions about Ford effects (d'Aspremont et al., 1991) or about price expectations (Kaas, 1998), IU can appear in overlapping generations models. For instance, even when the old have unit-elastic demand, the aggregate demand can be inelastic. Let us denote by $F(p)$ and $G(p)$ respectively the demand of the young and that of the old. The aggregate demand can be inelastic if the demand of the young is also inelastic $\left(\varepsilon_{F}(p)<1\right)$ and the demand of the old ${ }^{10}$ is negligible $(G(p) / D(p) \approx 0)$.

Furthermore, the presence of an old generation definitively ceases to be an obstacle to IU when the economy contains several sectors. D'Aspremont et al. (1991) showed that when the old can consume in different sectors, ${ }^{11}$ their demand is no more iso-elastic and depends on the intersectoral elasticity of substitution.

In contrast to these considerations, a specific problem of the overlapping generations model has received no attention in the literature we survey. In this model, the young have shares and earn profits. At the end of their youth, it is implicitly assumed that these shares 'disappear'. However it seems more reasonable to assume that these shares are sold or given away to the next generation. In both cases, the demand of the old is no longer unit-elastic.

To conclude sub-Section 3.2 on the preferences let us emphasise its main points. The consumers' preferences are the direct link between demand and the price. One needs to remember that when the agents are homogeneous, the more complementary the goods are the larger the firm's market power is. On the contrary when the agents are heterogeneous, it is less likely that the price elasticity of the overall demand takes low values.

\subsection{The role of price expectations}

So far we have studied the price elasticity of the demand for the good by assuming that this demand was directly dependent on the current price. In addition to this direct link and as soon as the underlying model is dynamic, the demand also depends (indirectly) on the current price through the expected price denoted $p^{e}$. Then, the demand is a function of two variables, i.e. $D\left(p, p^{e}\right)$. The future price is expected from past and present prices through an expectation function. Without loss of generality, we assume that this function has a single variable ${ }^{12}$ and is denoted by $\psi(p)$. Moreover, we assume that $\psi^{\prime}(p) \geqslant 0$, i.e. the expected price is a non-decreasing function of the current price. We denote by $e=p\left(\psi^{\prime}(p) / \psi(p)\right)$ the (present) price elasticity of the expectation function. It takes non-negative values and is assumed to be constant. 
By substituting the expectation function into the expected future price, the demand for the good becomes $D(p, \psi(p))$ and its price elasticity ${ }^{13}$ is then:

$$
\varepsilon_{D}(p)=e+(1-e) \varepsilon_{C}(p)
$$

where $\varepsilon_{C}(p)$ is the price elasticity ${ }^{14}$ of the demand in the static case (i.e. when the demand has a single variable, namely the present price).

It is well known that in general equilibrium models, the choice of a specific expectation function is crucial. Grandmont (1977) showed that as soon as the expectation function is non unit-elastic, it has a direct influence on the temporary general equilibrium. The study of IU requires that, from equation (3), the links between the elasticity of expectations and the second part of condition (C2) are established. For that purpose, two polar cases are studied and thereafter the general case.

\subsubsection{First case: unit-elastic expectations $(e=1)$}

From (3), we obtain $\varepsilon_{D}(p)=1$. Thus, IU cannot exist (independently of any other assumptions). By considering this result, Dixon and Rankin (1994) deduced that IU is due to non-unit-elastic expectations. However, the aim of the present paper is to show that for any expectation functions, consumers' preferences and Ford effects are by themselves decisive for the existence (or the non-existence) of IU. Unit-elastic expectations are sufficient to avoid IU but the non-existence of IU can prevail under other expectation functions.

\subsubsection{Second case: inelastic (or zero-elastic) expectations $(e=0)$}

From (3), we obtain $\varepsilon_{D}(p)=\varepsilon_{C}(p)$. The latter equality shows us that IU is going to depend directly ${ }^{15}$ on the demand. However, we first have to deal with the singular assumption of inelastic (or zero-elastic) expectations. Two interpretations are possible, related to the model's structure.

First interpretation: the model is static. In this case the demand for the good and its price elasticity are not dependent on expectations. This is the framework considered by d'Aspremont et al. (1984, 1989a, 1989b), Dehez (1985), Silvestre (1990). With specific assumptions on consumers' preferences and Ford effects, these authors demonstrated that IU might exist. However, the introduction of (inelastic) expectations in a static model can be considered a bit dubious. Indeed expectations are introduced in a static framework. In fact, this is not inconsistent, it is simply an extension of Hart's (1982) paper. Rankin (1992) showed that the non-produced good considered by Hart might be interpreted as money. The study of the equilibrium of the static model is then close to the study of a monetary temporary equilibrium. Finally, the assumption of inelastic expectations is fully relevant because as Patinkin (1965) and Grandmont (1983) pointed out, it is a necessary condition for monetary policy to be effective.

Second interpretation: the model is dynamic. Schultz (1992) initiated this approach. He studied the occurrence of IU in an overlapping generations model 
(OG model in what follows). In his model, each agent lives two periods, being young and then old. When young, the agent has to take decisions on the basis of the expected price. With inelastic expectations, the price elasticity only depends on preferences and on Ford effects. Without Ford effects, the existence of an old generation (with unit-elastic demand) is sufficient to exclude IU. In the same model but with full integration of Ford effects, d'Aspremont et al. (1991) conclude that IU may appear. Both results show that in spite of Dixon and Rankin's (1994) ${ }^{16}$ point of view, there are elements (other than expectations) which influence the existence of IU, even when expectations are non-unitelastic.

This second sense of the inelastic expectations is open to criticism. Indeed, Schultz (1992) as well as d'Aspremont et al. (1991) associated this assumption with rational expectations. However, the latter are usually considered as the asymptotic outcome of a learning process. According to Kaas (1998) the assumption of price inelastic rational expectations is quite strong because it is equivalent to assume that the learning processes are price inelastic. The latter assumption is totally different from what is done in most of the learning literature. ${ }^{17}$

\subsubsection{The general case $(e \neq 0$ and $e \neq 1)$}

This is the case studied by Kaas (1998). Following the previous discussion, he rejected inelastic price expectations and also considered that unit-elastic expectations are a particular case. Kaas showed that without Ford effects and with standard preferences and also elastic expectations, there exists a continuum of stationary equilibria with IU. In fact, a dynamic setting is not consistent with a nominal wage equal to zero. So, IU is defined as an equilibrium with, at arbitrary low real wages, an employment level below the full employment level.

To conclude sub-section 3.3 on expectations let us emphasise its main points. Expectations play a central part in the determination of the price elasticity of overall demand. They influence it through the expected price. When expectations are unit elastic, IU is impossible, while all possible outcomes may arise when this assumption is relaxed.

\subsection{Ford effects (or income feedback effects)}

So far the ingredients we have considered influence directly the overall price elasticity of the overall demand. In both cases, the income which supports the demand has been considered as a parameter. We are going to modify this assumption. Indeed the effects of the income are far from being negligible: it can 'indirectly' influence the price elasticity. As commonly known, the income is, at a macroeconomic level, equal to the value of output (e.g. the sum of wages and profits). A long time ago the Keynesian approach had already emphasised this double nature of income: it is the link between the production process and the global expenditure. At the market level, the same link exists between the supply and the demand for the good but its size depends on the number of markets in the 
economy and on the relationships between these markets. Thus, each imperfectly competitive firm knows that the income of its customers depends on its own strategies. When these feedback effects are taken into account, the expression of the demand is modified (and also the expression of its price elasticity). These effects are called 'Ford effects' because Ford (1922, p. 124) was the first who understood the multiplier effect associated with wages: 'I believe in the first place that, all other considerations aside, our own sales depend in a measure upon the wages we pay'.

Following Ford's analysis, d'Aspremont et al. initially integrated the feedback effects only for wages. In this case and following the methodology of Marshak and Selten (1974), profits are treated in a parametric manner and thereafter they are adjusted to their true value at equilibrium. The following papers on IU adopted three different strategies with respect to Ford effects. In the first one (d'Aspremont et al., 1989b, 1990, 1991), income feedback effects are fully integrated. These effects are limited to wages in the second one (d'Aspremont et al., 1984, 1989a) and are neglected in the third one (Dehez, 1985; Kaas, 1998; Schultz, 1992; Silvestre, 1990). The latter case means that firms are treating consumers' income as exogenous to their own actions. This corresponds to Hart's approach. In his model, the economy contains a large number of local markets (or sectors), each one being a reduced version of the entire economy. Moreover, Hart assumed that agents who received income from firms of a given sector could only consume the products of the other sectors.

Starting from Hart's framework, Lasselle and Svizzero $(1998,2001)$ connected the size of Ford effects to the economy's structure. Moreover, each agent earns income from firms of a single sector and buys goods in a single sector. As consumers, agents are distributed uniformly across the different sectors of the economy, including the sector where they are working (and thus from which they earn income). There are always Ford effects because a fraction of the consumers of a firm's product earns their income from the firm. This fraction is inversely proportional to $1 / \mu$, the number of sectors (an integer of course), with $\mu \in] 0,1]$. When the economy contains a single sector $(\mu=1)$, the Ford effects are fully taken into account while their integration decreases as the number of sectors increases ( $\mu$ tends to zero).

In a given sector, the imperfectly competitive firms are facing a demand supported by an income denoted $I$. This income has two components, i.e. $I=A+\mu p Y$. The first component, denoted $A$, is exogenous to the actions of the firms of the sector concerned. It is the income provided by firms from the other sectors. The second component corresponds to Ford effects. In fact, in this sector, the value of production is $p Y$ and it is distributed (as income) by firms through wages and profits. This income is uniformally distributed across sectors, then a fraction $\mu$ of this income is allocated to consumers of this sector and supports the demand addressed to firms of that sector.

With a representative consumer, the demand (in a given sector) is $D(p)=(\alpha(p) / p)(\mu p Y+A)$ where $\alpha(p) \in] 0,1[$ is the budget share allocated to consumption and defined as a function of the current price. The price elasticity of 
the demand for the good is: ${ }^{18}$

$$
\varepsilon_{D}(p)=1+\frac{\varepsilon_{\alpha}(p)}{1-\mu \alpha(p)}
$$

with $\varepsilon_{\alpha}(p)=-p\left(\alpha^{\prime}(p) / \alpha(p)\right)$.

Two conclusions can be deduced from equation (4). First, for any Ford effects (i.e. for any $\mu$ ), IU only appears if $\varepsilon_{\alpha}(p)$ takes negative values. This condition depends on assumptions about the demand. Thus, a necessary condition for IU to exist is that the budget share be an increasing function of the price. Second, when $\varepsilon_{\alpha}(p)$ takes negative values, we get $\partial \varepsilon_{D}(p) / \partial \mu<0$, i.e. the more integrated Ford effects are, the more inelastic the demand is and then the existence of IU is easier.

Both conclusions summarize and are equivalent to that obtained in papers set in the static model. Indeed, IU is consistent with any size of Ford effects.

Lasselle and Svizzero $(1998,2001)$ also studied the influence of Ford effects on IU in an OG model. In this model, the young's demand is similar to that previously defined in the static model. In fact, the income issued from the production is only distributed (by firms) to the young. As it is usual in this literature, the old's demand is equal to their real money balance. Then, in a given sector, the demand expressed by young and old is:

$$
D\left(p, p^{e}\right)=\frac{\alpha\left(p, p^{e}\right)}{p}(\mu p Y+A)+\frac{M}{p}
$$

Although the model is dynamic, the expectation function is not specified. This is equivalent to assuming (implicitly) that price expectations are inelastic. The price elasticity of the demand for the good is: ${ }^{19}$

$$
\varepsilon_{D}(p)=1+\frac{\alpha\left(p, p^{e}\right) \varepsilon_{\alpha}\left(p, p^{e}\right)}{1-\mu \alpha\left(p, p^{e}\right)}
$$

The study of equation (5) leads to the two conclusions already deduced from equation (4). However the existence of IU is based on more restrictive conditions than in the static model.

Schultz (1992) demonstrated that without Ford effects ( $\mu$ close to zero), full employment prevails for a sufficiently low wage. Lasselle and Svizzero $(1998,2001)$ strengthened Schultz's result. They demonstrated ${ }^{20}$ that IU could exist only if the economy contains a single sector $(\mu=1$; this is the case considered by d'Aspremont et al. (1991) where Ford effects are fully taken into account). When there are at least two sectors in the economy, they get a full employment equilibrium if the nominal wage is flexible. This outcome is due, on the one hand, to the fact that the existence of an old generation limits firms' market power and, on the other hand, to the fact that the demand of the young is more elastic when Ford effects are not fully incorporated by firms. Let us recall that Schultz (1992) and Lasselle and Svizzero $(1998,2001)$ both assumed that rational expectations were price inelastic. One should not conclude that IU hardly ever occurs (it is only when expectations are 
price inelastic that it hardly ever occurs). Finally, the study of the static as well as the dynamic model, proves that Ford effects play an influential part in the existence of IU. The more these effects are taken into account, the larger firms' market power is and then the existence of IU is more likely.

\section{Conclusion}

In economies with imperfect product markets, the general equilibrium can exhibit unemployment at any wage. This unemployment has been labelled 'involuntary'. Even if this label gives rise to semantic discussion, the concept of IU is powerful. It shows that unemployment can appear even with a competitive labour market. In other words, an imperfect product market is a sufficient condition to generate unemployment. Indeed, the imperfectly competitive firms' supply function can be upper bounded at a level less than the full employment one. Of course, the demand for the good has an influence on the firms' supply function. More specifically, its price elasticity must take low values (at low prices) for IU to appear. The existing literature has focused its attention on the nature of the demand. Three features have been extensively studied: consumers' preferences, price expectations and Ford effects.

Consumers' preferences determine the direct link between the demand and the price. The more complementary the goods are, the larger firms' market power is. On the contrary consumers' heterogeneity (which is inherent in OG models) leads to a more elastic demand. The reason is that the old's demand (equal to their real money balances) is unit-elastic.

Expectations also play a central part. They influence the demand through the expected price. When they are unit-elastic, IU is not possible while everything may happen with non-unit-elastic expectations.

Finally, Ford effects affect the demand through consumers' income. The size of these effects depends on the economy's structure. This size is inversely correlated to the number of product markets (or sectors). The smaller the number of markets is, the larger Ford effects are, and the greater firms' market power is.

It is important to note that these three elements are independent of each other. Several combinations of them can lead to IU. Of course, it is possible in theory, but not very reasonable, to link the existence of IU to consumers' preferences or expectations. Indeed, if we assume, as is conventional, that the latter are unit-elastic or the former are Cobb-Douglas, then IU cannot exist, as we have shown. Assumptions about Ford effects are certainly a more reasonable way of generating the existence of IU. In real economies, the globalization process leads to a smaller number of highly concentrated product markets, i.e. to conditions which are more likely to be consistent with strong income feedback effects. The possible existence of other influential features is a promising direction for future research.

\section{Appendix 1: Price elasticity and expectations}

We assume that $p^{e}=\psi(p)$ and $\psi^{\prime}(p) \geqslant 0$, i.e. the expectation function is non decreasing w.r.t. the current price. We deliberately neglect past prices in this 
function. By substituting the expectation function $\psi(p)$ into the demand $D\left(p, p^{e}\right)$, we get $D(p, \psi(p))$. When preferences are homothetic, the demand function is homogeneous of degree -1 . By applying Euler's theorem, we obtain:

$$
D(p, \psi(p))=\frac{1}{\psi(p)} D\left(\frac{p}{\psi(p)}\right)
$$

and

$$
\frac{\partial}{\partial p} D(p, \psi(p))=\frac{1}{\psi(p)^{2}} \frac{\partial}{\partial\left(\frac{p}{\psi(p)}\right)} D\left(\frac{p}{\psi(p)}\right)
$$

By using these expressions and by

$$
\varepsilon_{C}(p)=-\frac{p}{\psi(p)} \frac{1}{D\left(\frac{p}{\psi(p)}\right)} \frac{\partial}{\partial\left(\frac{p}{\psi(p)}\right)} D\left(\frac{p}{\psi(p)}\right),
$$

we deduce the price elasticity (see equation (3)) defined as

$$
\varepsilon_{D}(p)=-\frac{p}{D(p, \psi(p))} \frac{\partial}{\partial p} D(p, \psi(p)) .
$$

\section{Appendix 2: Price elasticity with variable Ford effects in the static case}

The demand for the good is defined by $D(p)=(\alpha(p) / p)(\mu p Y+A)$. When the market clears, we have $Y=D(p)$. The combination of the two previous expressions allows us to obtain the objective demand including Ford effects (e.g. the demand that firms face), $\tilde{D}(p)=(1 /(1-\mu \alpha(p)))(\alpha(p) A / p)$.

The expression for the price elasticity given by equation (4) can be computed from $\varepsilon_{D}(p)=-p \tilde{D}^{\prime}(p) / \tilde{D}(p)$.

\section{Appendix 3: Price elasticity with variable Ford effects in the dynamic case}

The demand for the good is $D\left(p, p^{e}\right)=\left(\alpha\left(p, p^{e}\right) / p\right)(\mu p Y+A)+M / p$.

When the market clears, we obtain $Y=D\left(p, p^{e}\right)$. From the two previous expressions, we get the objective demand function integrating Ford effects:

$$
\tilde{D}\left(p, p^{e}, A\right)=\frac{1}{1-\mu \alpha\left(p, p^{e}\right)}\left(\frac{\alpha\left(p, p^{e}\right) A+M}{p}\right)
$$


From this expression we compute $\tilde{D}_{p}^{\prime}\left(p, p^{e}, A\right)$, the first derivative of the demand w.r.t. the current price, the exogenous component of the income (denoted by $A$ ) being considered as a parameter. The latter one is adjusted to its true value at the equilibrium $A^{*}$ such that:

$$
A^{*}=(1-\mu) p \tilde{D}\left(p, p^{e}, A^{*}\right) \Leftrightarrow A^{*}=\left(\frac{1-\mu}{1-\alpha\left(p, p^{e}\right)}\right) M
$$

By substituting this expression into the demand, we obtain the correctly conjectured demand:

$$
\hat{D}\left(p, p^{e}\right)=\frac{1}{1-\alpha\left(p, p^{e}\right)}\left(\frac{M}{p}\right)
$$

The price elasticity computed in equation (5) is deduced from the following definition:

$$
\varepsilon_{D}(p)=-p \frac{\tilde{D}_{p}^{\prime}\left(p, p^{e}, A^{*}\right)}{\hat{D}\left(p, p^{e}\right)}
$$

\section{Appendix 4: On the impossibility of IU with more than one product market}

In the dynamic case, the price elasticity (equation (5)) is given by $\varepsilon_{D}(p)=$ $1+\alpha\left(p, p^{e}\right) \varepsilon_{\alpha}\left(p, p^{e}\right) /\left(1-\mu \alpha\left(p, p^{e}\right)\right)$. The price elasticity of the budget share, denoted by $\varepsilon_{\alpha}(p)$, can be rewritten as $\varepsilon_{\alpha}(p)=\left(1-\alpha\left(p, p^{e}\right)\right)\left(\sigma\left(p, p^{e}\right)-1\right)$ where $\sigma\left(p, p^{e}\right)$ is the young's intertemporal elasticity of substitution (definitely positive).

Then, equation (5) can be rewritten as

$$
\varepsilon_{D}(p)=1+\frac{\alpha\left(p, p^{e}\right)\left(1-\alpha\left(p, p^{e}\right)\right)\left(\sigma\left(p, p^{e}\right)-1\right)}{1-\mu \alpha\left(p, p^{e}\right)} .
$$

From this expression, the condition excluding the existence of IU is:

$$
\left(1-\frac{1}{n}\right)\left(1-\mu \alpha\left(p, p^{e}\right)\right)>\alpha\left(p, p^{e}\right)\left(1-\alpha\left(p, p^{e}\right)\right)\left(1-\sigma\left(p, p^{e}\right)\right)
$$

With at least two markets $(\mu \leqslant 1 / 2)$, IU is impossible. Indeed, from the previous inequality:

The left-hand term exceeds $1 / 4$. The first bracket is larger than $1 / 2$ (because there are at least two firms in an oligopolistic market), the second bracket is also larger than $1 / 2$ when $\mu \leqslant 1 / 2$.

The right-hand term is less than $1 / 4$ (even when the elasticity of substitution is close to zero) because the budget share does not exceed unity.

Thus, the inequality is always fulfilled.

Q.E.D. 


\section{Acknowledgements}

We thank David Cobham and Alan Sutherland, University of St. Andrews and two anonymous referees for helpful comments and suggestions. All remaining errors are our own.

\section{Notes}

1. Ford effects are also called 'income feedback effects'. These effects are provided by the linkage between the income distributed by firms and the demand they face (see 3.4.)

2. Both approaches (objectivist and subjectivist) are detailed in Bonanno (1990).

3. The fix-price IS/LM model.

4. For instance, leisure must not enter into the utility function.

5. The technology is standard when the production function fulfills Inada's conditions.

6. The explanations given in the literature are only 'technical' explanations such as: '... such a sufficient condition is satisfied if, for a given per capita endowment of the nonproduced good, the per capita endowment of labour time is large enough.', Silvestre (1990, p. 903-04).

7. At a symmetric equilibrium, each firm produces the same amount of output. When cost functions are increasing, convex and identical among firms, the symmetry of the equilibrium is ensured.

8. In other words, the labour endowment is not fully used at the equilibrium.

9. See Section 3.4.

10. With of course $\varepsilon_{G}(p)=1$ that is to say, the demand of the old is unit-elastic.

11. These authors call this market structure 'Cournotian monopolistic competition'.

12. In fact, past prices are still present in the expectation function. However they are omitted in the presentation we give because the key variable of our analysis is the current price elasticity of the expectation function.

13. See appendix 1 .

14. See appendix 1.

15. i.e. IU is going to depend on consumers' preferences, see Section 3.2

16. See Section 3.3.1.

17. Marcet and Sargent (1989).

18. See appendix 2 .

19. See appendix 3.

20. See appendix 3.

\section{References}

d'Aspremont, Cl., Dos Santos Ferreira, R. and Gérard-Varet, L. A. (1984) Oligopoly and involuntary unemployment, CORE Discussion Paper No. 8408.

d'Aspremont, Cl., Dos Santos Ferreira, R. and Gérard-Varet, L. A. (1989a) Unemployment in a Cournot oligopoly model with feedback effects. Recherches Economiques de Louvain, 55, 1, 33-60.

d'Aspremont, Cl., Dos Santos Ferreira, R. and Gérard-Varet, L. A. (1989b) Unemployment in an extended Cournot oligopoly model. Oxford Economic Papers, 41, 490-505.

d'Aspremont, Cl., Dos Santos Ferreira, R. and Gérard-Varet, L. A. (1990) On monopolistic competition and involuntary unemployment. Quarterly Journal of Economics, 105, 895-919.

d'Aspremont, Cl., Dos Santos Ferreira, R. and Gérard-Varet, L. A. (1991) Imperfect 
competition, rational expectations and unemployment. In W. A. Barnett et al. (eds), Equilibrium theory and applications (pp. 353-81) Cambridge University Press, Cambridge.

Bénassy, J. P. (1987) Imperfect competition, unemployment and policy. European Economic Review, 31, 417-26.

Bénassy, J. P. (1994) Classical and Keynesian features in macroeconomic models with imperfect competition, Cepremap Working Paper No. 9418.

Blanchard, O. J. and Kiyotaki, N. (1987) Monopolistic competition and the effect of aggregate demand. American Economic Review, 77, 647-66.

Bonanno, G. (1990) General equilibrium theory with imperfect competition. Journal of Economic Surveys, 4, 297-328.

De Vroey, M. (1999) From labor rationing to involuntary unemployment: a conceptual elucidation. Eastern Economic Journal, 25, 315-30.

Dehez, P. (1985) Monopolistic competition and involuntary unemployment. Journal of Economic Theory, 36, 160-65.

Dixon, H. D. and Rankin, N. (1994) Macroeconomics and imperfect competition: a survey, Oxford Economic Papers, 46, 171-99.

Dixon, H. D. and Rankin, N. (1995) The New Macroeconomics. Imperfect Markets and Policy Effectiveness, edited by H. D. Dixon and N. Rankin, Cambridge University Press.

Ford, H. (1922) My life and work. In collaboration with S. Crowther, William Heinemann, Londres.

Grandmont, J. M. (1977) Temporary general equilibrium theory. Econometrica, 45, 53572.

Grandmont, J. M. (1983) Money and Value. Cambridge: CUP.

Hart, O. (1982) A model of imperfect competition with Keynesian features. Quarterly Journal of Economics, 97, 1, 109-38.

Kaas, L. (1998) Multiplicity of Cournot equilibria and involuntary unemployment. Journal of Economic Theory, 80, 332-49.

Keynes, J. M. (1936) The general theory of employment, interest and money. Collected writings of J. M. Keynes (London: St. Martin Press for the Royal Economic Society, 1973).

Lasselle, L. and Svizzero, S. (1998) Existence of involuntary unemployment: the role of expectations and feedback effects. CRIEFF Working Paper No. 9822.

Lasselle, L. and Svizzero, S. (2001) The impossibility of underemployment with more than one product market, Oxford Economics Papers, 53, 157-165.

Lindbeck, A. (1998) New Keynesianism and aggregate economic activity. Economic Journal, 108, 167-80.

Mankiw, N. G. and Romer, D. (1991) New Keynesian Economics, vol I and II, edited by N. G. Mankiw and D. Romer, Cambridge: MIT Press.

Marcet, A. and Sargent, T. (1989) Convergence of least squares learning mechanisms in self-referential linear stochastic models. Journal of Economic Theory, 48, 337-68.

Marshak, T. and Selten, R. (1974) General equilibrium with price-making firms, Berlin: Springer verlag.

Negishi, T. (1961) Monopolistic competition and general equilibrium. Review of Economic Studies, 28, 196-201.

Novshek, W. (1985) On the existence of Cournot equilibrium. Review of Economic Studies, $52,85-98$.

Patinkin, D. (1965) Money, interest and prices. Londres: Harper and row.

Pigou, A. C. (1920) The Economics of Welfare. London: Macmillan.

Rankin, N. (1992) Imperfect competition, expectations and the multiple effects of monetary growth, Economic Journal, 102, 743-53.

Robinson, J. (1933) The Economics of Imperfect Competition. London: Macmillan.

Schultz, C. (1992) The impossibility of involuntary unemployment in an overlapping 
generations model with rational expectations. Journal of Economic Theory, 58, 1, 6176.

Silvestre, J. (1990) There may be unemployment when the labour market is competitive and the output market is not. Economic Journal, 100, 899-913.

Silvestre, J. (1993) The market power foundations of macroeconomic policy. Journal of Economic Literature, 31, 105-41.

Yellen, J. L. (1984) Efficiency-Wage Models of Unemployment, American Economic Review, 74, 200-205. 